\title{
Siyah İncir Sineği'nin (Silba adipata Mcalpine, Diptera: Lonchaeidae) Aydın İlinde İncir Bahçelerinde Bulunma Oranı, Popülasyon Değişimi ve Bazı Biyolojik Özellikleri
}

\author{
Eşref TUTMUŞ ${ }^{1}$ (D), Tülin AKŞiT ${ }^{* 2}$ \\ ${ }^{1}$ Tarım ve Orman Bakanlığı, Incir Araştırma Enstitüsü Müdürlüğ̈̈ AYDIN-TÜRKIYE \\ ${ }^{2}$ Aydın Adnan Menderes Üniversitesi, Bitki Koruma Bölümü, AYDIN-TÜRKIYE
}

\begin{abstract}
Öz: Silba adipata McAlpine 1956'nın (Diptera: Lonchaeidae) incir bahçelerinde bulunma oranı, popülasyon değişimi ve bazı biyolojik özellikleri incelenmiştir. Denemeler Ficus carica cv. Sarılop, F.carica cv. Bursa siyahı ve F.carica cv. caprificus çeşitlerinde yürütülmüştür. Denemelerde hexanol, amonyumsülfat ve incir sütü (incir ağacı özsuyu) karışımını içeren besin tuzakları kullanılmıştır. Aydın ilinin tüm ilçelerinin S.adipata ile bulaşık olduğu saptanmıştır. Sarılop çeşidinde bulaşık meyve oranının (ağaç üzerindeki ve yere düşmüş meyvelerin toplamında) 2011, 2012, 2013 yıllarında sırasıyla \% 3.53, \% 2.06 ve \%3.4 olduğu belirlenmiştir. Sarılop meyvelerinde çalışma yıllarında yere dökülmüş meyvelerde bulaşıkılık oranı \%20-40 arasında değişmiştir. Bursa siyahında 2013 yılında bu oran \%10, yerdeki meyvelerde \%64' tür. Sarılop bahçelerinde seksüel indeks 0.7 olarak bulunmuştur. Incir bahçelerinde zararlının ergin ve yumurtaları mayıs-aralık ayları arasında görülmüştür. Sarılop bahçelerinde en yüksek ergin popülasyonu temmuz ve eylül, erkek incir bahçesinde eylül ve ekim aylarında saptanmıştır. Bir incir meyvesinden en çok yumurta (yumurta/meyve) ebe meyvelerinden (84 yumurta) elde edilmiş, onu sırasıyla, iyilop (67 yumurta), boğa (12 yumurta) ve ilek (5 yumurta) meyveleri izlemiştir. Yellop ve sonlop meyvelerinde yumurtaya rastlanmamıştır. Çalışma yıllarında en fazla yumurta da ebe meyvelerinden elde edilmiş olup, onu iyilop, boğa ve ilek meyveleri izlemiştir. En çok yumurta iyilop meyvelerinde temmuz ve eylül aylarında, ebe meyvelerinde eylül ayında, ilek meyvelerinde mayıs ve haziran aylarında, boğa meyvelerinde mayıs ayında saptanmıştır. Larva $8.18 \pm 1.35$ ve pupa $7.84 \pm 0.13$ günde geliş̧miştir.
\end{abstract}

Anahtar kelimeler: Silba adipata, Lonchaeidae, Sarılop, caprifig, Siyah incir sineği, MacPhail trap

The Rate of Infestation, the Population Fluctuation and Some Biological Characteristics of Black Fig Fly (Silba adipata Mcalpine, Diptera: Lonchaeidae) in Fig Orchards in Aydın Province

\begin{abstract}
The rate of infestation, some biological characteristics, and population fluctuation of Silba adipata McAlpine (Diptera: Lonchaeidae) in fig orchards in Aydın province were studied. The trials were conducted in Ficus carica cv. Sarılop, F.carica cv. Bursa siyahı and F.carica Cv. caprificus varieties. Bait traps containing a mixture of hexanol, ammonium sulfate and fig milk (fig tree extract) were used in trials. It was determined that all districts of Aydın province were infested with S. adipata. In the years 2011, 2012 and 2013, the infestation rates in fruits of the Sarılop variety (the sum of the fruit on the tree and on the ground) were determined as $3.53 \%, 2.06 \%$ and $3.40 \%$, respectively. The rates of infestation among the fruits fallen on the ground were changed between $20-40 \%$ in Sarilop in study years. In Bursa siyahı, this rate among fallen ones was 64\%. Sexual index in Sarlop orchards was found to be 0.7. The adults and eggs of the pest were seen between May-December in the orchards. The highest adult population was detected in the Sarlop orchards in July and September, and in the caprifig orchard in September and October. The most numerous eggs in a fig fruit (egg/fruit) were obtained from mammoni fruits (84 eggs), followed by the maincrop fruits (67 eggs), mamme fruits (12 eggs) and profichi fruits (5 eggs), respectively. No egg was found in breba and lastcrop fruits. The most number of eggs during the study years was also obtained from mammoni fruits, followed by maincrop, mamme and profichi fruits. The most numerous eggs were determined in maincrops in July and September; in breba in September; in profichi in May and June, in mamme fruits in May. The larvae and pupae were developed in $8.18 \pm 1.35$ days and $7.84 \pm 0.13$ days, respectively.
\end{abstract}

Keywords: Silba adipata, Sarılop, caprifig, Black fig fly, MacPhail trap

\section{GíRiş}

İncir, Türkiye tarımında ekonomik önemi olan en önemli ürünlerden birisidir. İncir üretimi sırasında karşılaşılan sorunlar arasında hastalık ve zararlılar ilk sıralarda yer alır (Özar vd.,1986). İncir zararlıları arasında Silba adipata McAlpine (Diptera: Lonchaeidae) da yer almaktadır. Zararlının Türkiye'de bulunduğu ilk olarak İyriboz tarafından 1931 yılında belirlenmiştir (İyriboz, 1934; 1940). Fakat tür yanlış teşhis sonucunda Lonchea aristella Beck. olarak isimlendirilmiş ve birçok yayında da bu isim kullanılmıştır (Ferguson ve ark.,1990). Silba adipata'nın Türkiye'nin de aralarında bulunduğu Akdeniz ve Ortadoğu Ülkelerinde yeşil incir meyvelerinde önemli zararlara neden olduğu bildirilmiştir (Condit, 1947). Silba adipata larva ve yumurtalarının meyve içerisinde bulunması, toprakta pupa olması ve yılda çok döl vermesi kontrolünü

*Sorumlu Yazar: tulinaksit@adu.edu.tr Bu makale Eşref TUTMUŞ tarafından hazırlanan yüksek lisans tezinin bir bölümü olup, Tarım ve Orman Bakanlığı Tarımsal Araştırmalar ve Politikalar Genel Müdürlüğü (TAGEM-BS11/04-05/01-17) tarafından desteklenmiştir

Geliş Tarihi: 17 Kasım 2021

Kabul Tarihi: 22 Aralık 2021 
güçleştirmektedir. Son yıllarda özellikle Yunanistan ve İsrail'de besin çekici tuzaklarla popülasyon değişiminin izlendiği az sayıda çalışmaya rastlanmıştır (Katsoyannos, 1983; Katsoyannos ve Guerin 1984; Raz, 1998). Türkiye'de S.adipata hakkında İyriboz (1940)'un bildirimlerinden başka ayrıntılı kayıt bulunmamaktadır. Zararlının Aydın ve İzmir illerinde yer ve yıla göre değişmekle birlikte önemli meyve kayıplarına neden olduğu bilinmektedir.

Bu nedenle ele alınan bu çalışma, Aydın ilinde S.adipata'nın durumunu ve bazı biyolojik özelliklerini ortaya çıkarmak ve McPhail besin tuzaklarıyla ergin popülasyon değişimini belirlemek amacıyla, erkek ve dişi incir bahçelerinde yürütülmüş ve zararlının biyolojik döngüsünde erkek ve dişi ağaç meyvelerinin önemi ortaya konmuştur.

\section{MATERYAL VE YÖNTEM}

Çalışmada Ficus carica cv. Sarılop, Ficus carica cv. Bursa siyahı, erkek incir (Ficus carica cv. caprificus) çeşitleri ile Silba adipata McAlpine'nın biyolojik dönemleri kullanılmıştır.

Silba adipata McAlpine'nın yayılışı ve bulaşık meyve oranlarının belirlenmesi

S.adipata'nın yayılışını belirlemek amacıyla Aydın'ın tüm ilçelerinde (17 ilçe) ve bu ilçelere bağlı 38 köy/mahalledeki 76 bahçede, ileklemeden sonra, iyilop meyvelerinin çapları 38-40 mm'ye ulaştığında, 12-26 Temmuz 2011 ile 5-19 Temmuz 2012 tarihleri arasında sürvey çalışmaları yapılmıştır. Sürvey, ilçelerdeki toplam ağaç varlığının \%0.01'ini oluşturacak şekilde incelenen toplam 760 adet ağaçta, Lazarov ve Grigorov (1961)'un yöntemine göre gerçekleştirilmiştir (Çizelge 1). Ileklemeden sonra 2013 yılında sadece 10 Sarılop ve 10 Bursa siyahı bahçesinde sayım yapılmıştır.

Çizelge 1. Bahçe büyüklüğüne göre incelecek ağaç sayıları (adet) (Lazarov ve Grigorov, 1961)

\begin{tabular}{cc}
\hline $\begin{array}{c}\text { Sürvey bahçelerindeki toplam ağaç sayısı } \\
\text { (Adet) }\end{array}$ & $\begin{array}{c}\text { İncelenecek } \\
\text { ağaç sayısı } \\
\text { (Adet) }\end{array}$ \\
\hline $1-20$ & $\begin{array}{c}\text { Tüm ağaçlar } \\
21-70\end{array}$ \\
& $10-30$ \\
$71-150$ & $31-40$ \\
$151-500$ & $41-80$ \\
$501-1000$ & $\begin{array}{c}\text { Toplam } \\
\text { ağaçların } \\
\% 15^{\prime} i\end{array}$ \\
\hline
\end{tabular}

Belirlenen ağaçların dört yönünden olmak üzere, yerden 1.5-2.0 m yükseklikteki toplam 12 adet sürgün üzerinde bulunan tüm meyveler ile sürgün üzerinde bıraktıkları izlerden dökülmüş olan meyvelerin sayısı belirlenmiş ve böylece sürgünler üzerindeki toplam meyve sayıları ortaya çıkarılmıştır. Daha sonra her ağaçtan 40 ve varsa yere dökülmüş meyvelerden de 40 'ar adet incelenerek zararlıyla bulaşık olup olmadıkları ve diğer nedenlerden kaynaklanan dökülmeler kaydedilmiştir. Elde edilen verilerle Bora ve Karaca (1970)'nın tartılı ortalama yöntemine göre köy ve ilçelere ait zarar oranları hesaplanmıştır.

Silba adipata McAlpine'nın ergin popülasyon değişiminin belirlenmesi

Zararlının popülasyonu Germencik ilçesinin Erbeyli ve Mursalı köylerindeki birer Sarılop incir bahçesi ile İncirliova ilçesindeki bir erkek incir (caprifig, ilek) bahçesinde 20112013 yılları arasında izlenmiştir. Mursallı'daki bahçede zararlının popülasyonu ilk iki yıl çok düşük olduğu için 2013 yılında tuzak asıımamıştır. Çalışmada Katsoyannos (1983) ile Katsoyannos ve Guerin, 1984'ün önerdiği tuzak içerikleri birleştirilerek oluşturulan hexanol (\%3) ve amonyumsülfat (\%2) ve incir sütü (\%1) karışımını içeren McPhail tuzağı kullanılmıştır. Tuzaklar bahçelere 23 Şubat 2011, 29 Şubat 2012 ve 06 Mart 2013 tarihlerinde asılmış, ilk erginler yakalanıncaya kadar her gün, daha sonra haftada bir kez kontrol edilmiş ve 7 Aralık 2011, 5 Aralık 2012 ve 25 Aralık 2013 tarihlerinde kaldırılmıştır.

\section{Meyvelerdeki yumurta popülasyonunun belirlenmesi}

Bir erkek (caprifig) ve bir dişi (Sarılop) incir bahçesinden 27 Mart-29 Aralık 2013 tarihleri arasında her hafta, incirin fenolojisine göre boğa, ilek, ebe, yellop, iyilop ve sonlop meyvelerinden beşer adet alınarak laboratuvara getirilmiş ve ostiol pulları arasındaki yumurtalar Stereobinoküler mikroskop altında sayılmıştır.

Silba adipata McAlpine'nın bazı biyolojik özelliklerinin belirlenmesi

Bahçelerden toplanan meyvelerdeki yumurtalardan yeni çıkan larvalar kıl fırça yardımıyla alınarak ikiye bölünmüş incir meyvelerinin üzerine bırakılmış ve pupa oluncaya kadar izlenmiştir $(n=10)$. Ayrıca, ağaçlardan toplanarak laboratuvara getirilen meyvelerin içerisinde bulunan olgun larvalar tek tek pleksiglas petri kaplarında kültüre alınarak larva gelişme ve pupa olduktan sonra pupa gelişme süreleri belirlenmiştir ( $n=13$ ).

\section{BULGULAR VE TARTIŞMA}

Silba adipata McAlpine'nın yayılışı ve bulaşık meyve oranları

Aydın ilinde 17 ilçe ve onlara bağlı 38 köy/mahallede yapılan sayımlar sonucunda tüm ilçelerin (\%100), köylerin ise \%92'sinin zararlıyla bulaşık olduğu saptanmıştır. Sadece Çamköy (Germencik), Habibler (Incirliova) ve Başçayır (Köşk)'daki örnekleme yapılan birer bahçede zararlıya rastlanmamıştır. Sürvey sırasında 38-790 m yükseklikler arasındaki bahçelerde zararlı bulunmuştur. İyriboz (1940) 
tarafından Kızıltepe (Germencik), Erbeyli (Incirliova), Çobanisa (Kuyucak) köyleri ile Denizli'nin Sarayköy ve Izmir'in Bornova ilçelerinin zararlıyla bulaşık olduğu bildirilmiştir.

Yeşil, ham incir meyvelerinin ostiol pulları arasına bıraılan yumurtalardan çıkan larvalar meyve etinde açtıkları galerilerin içerisinde beslenir ve meyvelerin dökülmesine neden olur. Galerilerin içerisi zamanla kahverengileşir, larvanın gelişmesine bağlı olarak genişler. Son dönem olan üçüncü larva dönemine erişen bireyler gelişmesini tamamladıktan sonra meyve kabuğunda açtıkları deliklerden meyveyi terk ederek toprağın 2-10 cm derinliğinde pupa olurlar (İyriboz, 1940; Ülkümen ve ark., 1948; Giliomee ve ark., 2007). Farklı olarak Katsoyannos (1983), bir meyvede 63 adet pupa bulunduğunu bildirmiştir. Bazı meyvelerin meyve boşluklarında da larvalara rastlanmıştır. İlk zamanlar bulaşık meyveler dışarıdan belli olmaz, ancak ostiol pulları arasındaki yumurta, boş yumurta kabukları ve larvaların görülmesiyle meyvenin bulaşık olup olmadığı kolaylıkla anlaşılabilir. Zararlı ile bulaşık bazı meyvelerde kabarma ve hafif şekerlenme gibi erken olgunlaşma belirtileri ortaya çıkar ve bu meyveler normal olgunluk zamanından yaklaşık bir, birbuçuk ay önce dökülürler. Olgun meyvelerde ise bu belirtiler görülmez, larvalar meyve kabuğunu delmeye ihtiyaç duymadan meyvenin ostiol açıklığından dışarı çıkarlar. Olgun meyvelerin çürüdüğü de kayıtlıdır (Giliomee ve ark., 2007). Bu durumun zarar gören meyvelere bulaşan mikroorganizmalar nedeniyle ortaya çıktığı düşünülmektedir. $\mathrm{Bu}$ çalışma sırasında bu belirtiye rastlanmamıştır.

Çalışma sırasında erginlerin çatlamış, yarılmış olgun incir meyvelerinden sızan şekerli maddeler, kırılmış dal, kopmuş meyve veya yaprakların dala bağlı oldukları noktalardan sızan incir sütüyle ayrıca, Karadut (Morus nigra L.) meyveleriyle beslendikleri belirlenmiştir. Katsoyannos (1983), erginlerin çoğunlukla sabah ve öğleden sonra geç saatlerde benzer şekilde beslendiklerini, bitki özsuyu (incir sütü) kokusunun erginleri cezbettiğini bildirmiştir. Erginlerin incir meyveleri olgunlaşmadan önce Campsis radicans Juss çiçekleri (Katsoyannos, 1983) ve Ceroplastes rusci (L.)’nin şekerli dışkısıyla (İyriboz, 1940) beslendiği de kayıtlıdır. Zararlının Cezayir'de yılda 6, Yunanistan'da 4-6 döl verdiği saptanmıştır (Katsoyannos, 1983; Raz, 1998).

İlek arısı (Blastophaga psenes L., Hym.:Agaonidae) kışı boğa meyvelerinin içerisinde larva döneminde geçirdikten sonra ilek meyvelerine geçer ve bu meyveler tozlaşmada (ilekleme) kullanılır. Sağlıklı ve yeterli sayıda İlek arısının bulunması bu meyvelerin zarar görmemesine bağlıdır. Boğa meyvelerinden ilek meyvelerine $B$. psenes geçişinin olmaması ilek meyvelerinin dökülmesine neden olduğu için ilekleme döneminde polen ve İlek arısı kıtlığı ortaya çıkar. Aydın'da bu çalışma sırasında erkek incir ağaçlarının özellikle eylül ve ekim aylarındaki ebe meyvelerinde yumurta sayısının en yüksek düzeyde olduğu, yumurtadan çıkan larvaların gelişmelerini tamamladıktan sonra kışı geçirmek üzere toprağa inerek pupa oldukları, bu nedenle boğa meyvelerinde popülasyonun düşük olduğu görülmüştür. Sarılop bahçesinde ise ileklemeden sonra yeşil iyilop meyvelerinde popülasyonun yüksek olduğu, lokal bazı alanlarda meyve dökümlerinin meydana geldiği ve önemli ürün kayıplarının ortaya çıktığı görülmüştür.

Ficus carica cv. Sarılop çeşidinde bulaşık meyve oranları Aydın'ın ilçe ve köylerinde 2011-2013 yılları arasında belirlenmiş olan zararlıyla bulaşık iyilop meyve oranları Çizelge 2 ve 3'de verilmiştir. Iki yılda da bulaşık meyve oranı sırasıyla en yüksek Sultanhisar, Koçarlı, Bozdoğan, Karacasu ve Buharkent ilçelerinde saptanmıştır. Sadece Incirliova'da 2011 yılında iki (\%24.8 ve \%21), Nazilli'de bir bahçede (\%24.8) bulaşık meyve oranı \%20'nin üzerine çıkmış, diğer bahçelerde düşük bulunmuştur. Başçayır (Köşk), Çamköy (Germencik) ve Habipler (İncirliova) köylerinde iki yılda da bulaşık meyveye rastlanmamıştır. Sarılop çeşidinde 2011, 2012 ve 2013 yıllarında bulaşık meyve oranları sırasıyla \%3.53, \%2.06, \%3.40 (Çizelge 2 ve 3), yerdeki dökülmüş meyvelerde ise \%29, \%20ve \%40 olmuştur. İyriboz (1940), nisan ayında S.adibata larvalarının ilek meyvelerinde görülmesinden sonra meyve dökümlerinin başladığını, haziran ortasından temmuz ortasına kadar yeni doğmuş iyilop ve ebe meyvelerinde dökümlere neden olduğunu, 1933 yılında ebe meyvelerinde \%90meyve kaybı meydana geldiğini bildirmiştir. Katsoyannos ve Guerin (1984) tarafından Anagnostopulos (1939)'a atfen S. adipata'nın olgunlaşmamış incirlerde \%50, kışlayan yabani incirlerde (boğa) ise \% 90meyve kaybına neden olduğu kayıtlıdır.

Bursa siyahı çeşidinde 2013 yılında bulaşık meyve oranı \%10olmuş, en yüksek oran Çakmar Köyü’nde bir bahçede (\%27) saptanmış, onu sırasıyla Erbeyli (\%19.40), Güzelköy (\%16.30), Kavaklı (\%9), Umurlu (\%5.30-4.80), Sevindikli (\%5.20), Incirliova (\%40) ve Yazıdere (\%0.10) köyleri izlemiştir (Çizelge 3). Yere dökülmüş meyvelerde ise bulaşıklılık oranı \%64 bulunmuştur. Aydın'da, Bursa siyahı çeşidinin üretimi sınırlı olduğundan, sadece 10 bahçede örnekleme yapılabilmiştir. Bu nedenle zararlının çeşit tercihi konusunda kesin kanıya varabilmek için detaylı çalışmaların yapılmasının uygun olacağı düşünülmektedir. 
Siyah Incir Sineği'nin (Silba adipata Mcalpine, Diptera: Lonchaeidae) Aydın

Ilinde Incir Bahçelerinde Bulunma Oranı, Popülasyon Değişimi ve Bazı

Biyolojik Özellikleri

Çizelge 2. Aydın Illinin ilçe ve köylerinde 2011-2012 yıllarında Ficus carica cv. Sarılop çeşidinde Silba adipata McAlpine ile bulaşık meyve oranları

\begin{tabular}{|c|c|c|c|c|c|}
\hline \multirow[b]{2}{*}{ İlçe } & \multirow[b]{2}{*}{2011} & \multirow[b]{2}{*}{2012} & \multicolumn{3}{|c|}{ Bulaşık meyve (\%) } \\
\hline & & & Köy & 2011 & 2012 \\
\hline \multirow{7}{*}{ Nazilli } & & & Sailer & 0.1 & 0.0 \\
\hline & & & Kardeşköy & 0.6 & 0.6 \\
\hline & & & Haydarlı & 16.3 & 1.7 \\
\hline & & & Çamköy & 6.3 & 1.9 \\
\hline & 3.9 & 1.4 & Demirciler & 1.0 & 1.4 \\
\hline & & & Kestel & 1.0 & 1.6 \\
\hline & & & Yalınkuyu & 2.4 & 2.3 \\
\hline \multirow{5}{*}{ Germencik } & & & Bozköy & 0.2 & 0.1 \\
\hline & & & Çamköy & 0.0 & 0.0 \\
\hline & & & Ortaklar & 0.8 & 0.0 \\
\hline & & & Balatçık & 0.1 & 0.1 \\
\hline & 0.3 & 0.1 & Mursallı & 0.2 & 0.5 \\
\hline \multirow{4}{*}{ İncirliova } & & & Erbeyli & 16.0 & 2.5 \\
\hline & & & Arzular & 3.1 & 0.5 \\
\hline & & & Eğrek & 1.1 & 1.0 \\
\hline & 5.0 & 1.2 & Habipler & 0.0 & 0.0 \\
\hline \multirow{2}{*}{ Bozdoğan } & & & Pınarlı & 1.9 & 2.9 \\
\hline & 5.4 & 3.0 & Osmaniye & 9.0 & 3.0 \\
\hline \multirow{2}{*}{ Sultanhisar } & & & Salavatlı & 6.6 & 4.1 \\
\hline & 8.8 & 4.0 & Kılavuzlar & 11.0 & 3.9 \\
\hline \multirow{2}{*}{ Aydın } & & & Balıkköy & 1.9 & 0.2 \\
\hline & 1.9 & 1.0 & Kızılcaköy & 2.0 & 1.7 \\
\hline \multirow{2}{*}{ Kuyucak } & & & Kurtuluş & 1.2 & 0.8 \\
\hline & 1.9 & 1.4 & Çobanisa & 2.6 & 2.0 \\
\hline \multirow{2}{*}{ Buharkent } & & & Merkez & 3.0 & 5.5 \\
\hline & 2.5 & 3.1 & Savcıllı & 2.0 & 0.7 \\
\hline \multirow{3}{*}{ Köşk } & & & Yavuzlar & 12.6 & 12.6 \\
\hline & & & Uzundere & 0.5 & 0.1 \\
\hline & 4.4 & 2.6 & Başçayır & 0.0 & 0.0 \\
\hline Yenipazar & 3.0 & 1.4 & Merkezköy & 3.0 & 1.4 \\
\hline \multirow{2}{*}{ Koçarlı } & & & Yağcıdere & 5.4 & 4.2 \\
\hline & 7.2 & 10.1 & Mersinbelen & 8.9 & 16.0 \\
\hline Karacasu & 5.1 & 4.1 & Dereköy & 5.1 & 4.1 \\
\hline Söke & 1.1 & 0.6 & Merkez & 1.1 & 0.6 \\
\hline Kuşadası & 0.4 & 1.2 & Yeniköy & 0.4 & 1.2 \\
\hline Didim & 4.9 & 2.6 & Akköy & 4.9 & 2.6 \\
\hline Karpuzlu & 2.8 & 0.1 & Akçaabat & 0.1 & 0.1 \\
\hline Çine & 0.1 & 0.1 & Elderesi & 0.1 & 0.1 \\
\hline Ortalama & & & & 3.53 & 2.06 \\
\hline
\end{tabular}


Çizelge 3. Aydın'ın ilçe ve köylerinde 2013 yılında Ficus carica cv. Sarılop ve Ficus carica cv. Bursa siyahı çeşitlerinde Silba adipata McAlpine ile bulaşık meyve oranları

Ficus carica cv. Bursa siyahı Ficus carica cv. Sarılop

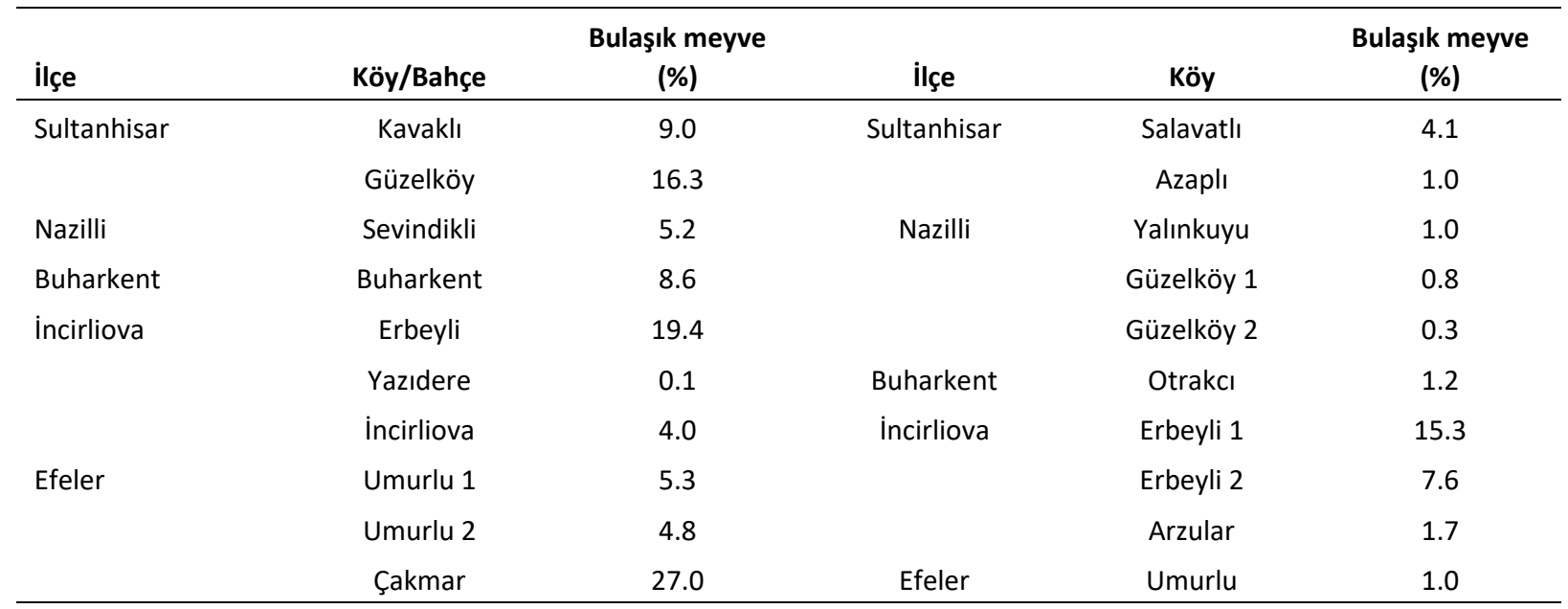

Ortalama 10.0

Ortalama

3.4

Ficus carica cv.caprificus bahçesinde ergin popülasyonu

McPhail tuzağı kullanılarak S.adipata ergin popülasyonu ve eşey oranı belirlenmiştir (Şekil 1a,b,c). Incirliova'daki erkek incir (caprifig) bahçesinde erginlerin tuzaklara ilk-son yakalanma tarihleri; 2011 yılında 1 Haziran-21 Kasım; 2012 yılında 23 Mayıs-28 Kasım; 2013 yılında 19 Haziran-11 Aralık olmuştur. En fazla ergin 26 Eylül 2011 tarihinde (156 ergin/tuzak) yakalanmış, aylık toplam ergin sayısı/tuzak 2011 yılında en yüksek eylül ayında (443 ergin) saptanmış, onu ekim (219 ergin), temmuz (113 ergin), ağustos (96 ergin), haziran (26 ergin), kasım (2 ergin) ve mayıs (1 ergin) ayları izlemiştir. Aralık, şubat, mart ve nisan aylarında tuzaklara ergin gelmemiştir.

Aynı bahçede 2012 yılında ilk yıla benzer şekilde ergin sayısı en yüksek noktaya 28 Eylül tarihinde ( 85 ergin) ulaşmış, aylık toplam ergin sayısı da en yüksek eylül ayında (221 ergin) olmuş, onu sırasıyla, ekim (110 ergin), ağustos (47 ergin), temmuz (30 ergin), haziran (7 ergin) ve mayıs (1 ergin) ayları izlemiştir (Şekil 1b). Tuzaklara kasım, aralık, şubat, mart ve nisan aylarında ergin yakalanmamıştır.

Bahçede, 2013 yılında da ilk iki yılda olduğu gibi en çok ergin 25 Eylül (380 ergin/tuzak) tarihinde elde edilmiştir (Şekil 1c). Aylara göre tuzak başına yakalanan toplam ergin sayıları eylül (631 ergin), ekim (127 ergin), temmuz (88 ergin), kasım (25 ergin), ağustos (9 ergin), haziran (8 ergin) ve aralık (1 ergin) aylarında saptanmıştır. Bahçedeki tuzaklarda şubat, mart ve nisan aylarında ergin görülmemiştir.

\section{Ficus carica cv. Sarılop bahçesinde ergin popülasyonu}

Tarım ve Orman Bakanlığı İncir Araştırma Enstitüsü'nün koleksiyon bahçesindeki Sarılop parseline asılan tuzaklarda ilk ve son erginler 2011, 2012 ve 2013 yıllarında sırasıyla, 15 Haziran-2 Kasım; 9 Mayıs-14 Kasım; 8 Mayıs-13 Kasım tarihlerinde saptanmış ve popülasyon en yüksek noktaya 18 Temmuz 2011 tarihinde (558 ergin/tuzak) ulaşmıştır. Tuzaklarda aylık yakalanan toplam ergin sayısı temmuz ayında en fazla olmuş (1030 ergin), onu sırasıyla eylül (570 ergin), ağustos (432 ergin), ekim (232 ergin) ve haziran (1 ergin) ayları izlemiştir. Tuzaklarda nisan ve mayıs aylarında ergine rastlanmamışırı (Şekil 1a).

İkinci yıl (2012), ilk yıl olduğu gibi popülasyon en yüksek noktaya 4 Temmuz tarihinde (482 ergin/tuzak) ulaşmıştır (Şekil 1b). Aylara göre tuzak başına yakalanan toplam ergin sayıları 2011 yılına benzer bulunmuş ve temmuz ayı ilk sırada (930 ergin) yer almış, onu ağustos (85 ergin), haziran (69 ergin), eylül (37 ergin) ve mayıs (1 ergin) ayları izlemiştir. Ekim, kasım, aralık, mart ve nisan aylarında ergine rastlanmamıştır.

Üçüncü yılda da (2013) en fazla ergin 3 Temmuz (101 ergin/tuzak) tarihinde yakalanmış, aylara göre en fazla ergin temmuz ayında (1030 ergin) saptanmış, onu haziran (755 ergin), eylül (231 ergin), ekim (126 ergin), ağustos (28 ergin), mayıs (1 ergin) ve kasım (1 ergin) ayları izlemiştir. Mart, nisan ve aralık aylarında ergin görülmemiştir (Şekil 1c). Bahçenin koleksiyon bahçesi olması nedeniyle çok sayıda incir çeşidinin bir arada bulunmasının zararlı popülasyonunu artırdığı ve diğer bahçelerden yüksek olmasına yol açtı̆̆ı düşünülmektedir.

Germencik ilçesi Mursallı köyündeki Sarılop bahçesinde (Şekil 1a,b) ilk ve son erginler tuzaklara 13 Temmuz-12 Ekim 2011; 20 Haziran-17 Ekim 2012 tarihlerinde yakalanmıştır. 

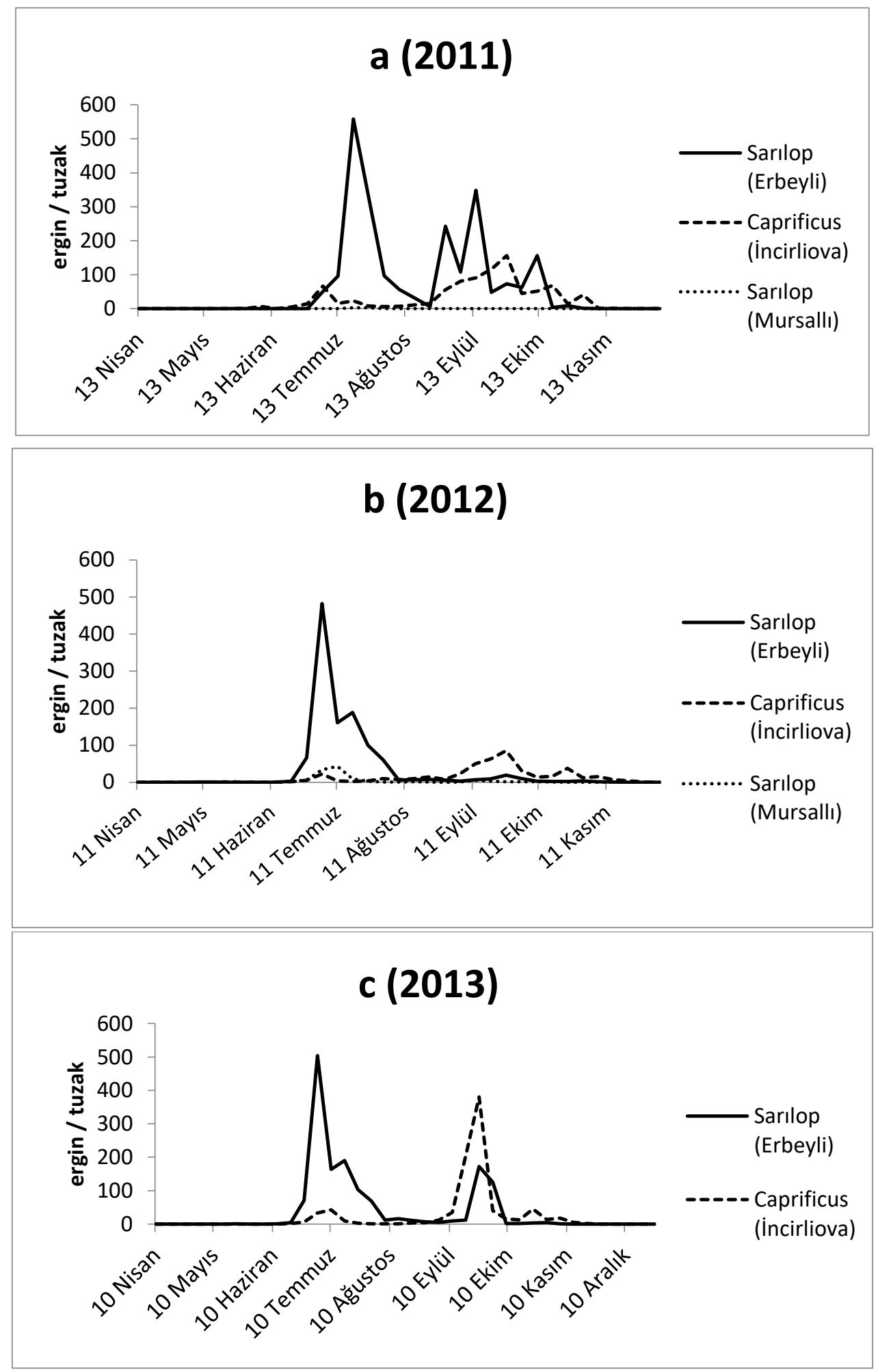

Şekil 1. Silba adipata McAlpine'nın 2011 (a), 2012 (b) ve 2013(c) yıllarında Aydın ilinin Germencik ve İncirliova ilçelerindeki dişi incir (Ficus carica cv. Sarılop) ve erkek incir (Ficus carica cv. caprificus) bahçelerinde McPhail tuzaklarına yakalanan erginlerin popülasyon değişimleri 
Bahçede S.adipata popülasyonu çok düşük olduğundan 2013 yılında tuzak asılmamıştır. En fazla ergin (3 ergin/tuzak) 18 Temmuz 2011 tarihinde yakalanmıştır. Tuzaklara yakalanan aylık toplam ergin sayıları değerlendirildiğinde 2011 yılında en fazla ergin temmuz ayında (6 ergin) yakalanmış, onu ağustos (1.4 ergin), eylül ve ekim ayları (0.6 ergin) izlemiştir. Kasım, aralık, mart, nisan, mayıs ve haziran aylarında ergine rastlanmamıştır. İkinci yıl (2012) yine en fazla ergin 11 Temmuz tarihinde (43/tuzak) yakalanmış, aylık toplam ergin/tuzak sayıları; temmuz (88 ergin), eylül (10 ergin) haziran (8 ergin), ekim ( 3 ergin) ve ağustos ( 2 ergin) olmuştur. Bahçede kasım, aralık, şubat, mart, nisan ve mayıs aylarında ergine rastlanmamıştır (Şekil 1a,b).

Elde edilen sonuçlara göre erkek incir (caprifig) bahçesinde ocak, şubat, mart ve nisan aylarında ergine rastlanmamış, mayıs ve aralık aylarında ise birer adet ergin elde edilmiştir. Sarılop bahçelerinde ise aralık, ocak, şubat, mart ve nisan aylarında ergin görülmemiş, mayıs ve haziran aylarında ise birer adet ergine rastlanmıştır. Farklı olarak İyriboz (1940), İzmir (Bornova)'de ilk erginlerin 21 Mart, ikinci döl erginlerinin ise haziran başında çıktığını bildirmiştir. İsrail'de ilk erginler 11 Mart tarihinde yakalanmış, 1988-1989 yıllarında popülasyonun haziran ortasından ağustos ortasına kadar yüksek düzeyde seyrettiği, fakat kış aylarında ergine rastlanmadığı (Raz, 1998), Güney Afrika'da ilk erginlerin 15 Kasım tarihinde görüldüğü bildirilmiştir (Giliomee ve ark., 2007).

Aydın'da erkek incir bahçesinde sıcaklıkların $20-30^{\circ} \mathrm{C}$, nispi nemin \%50-60 arasında olduğu eylül ve ekim aylarında, Sarılop bahçesinde ise sıcaklığın yükseldiği, nispi nemin düştüğü temmuz ve ağustos aylarında popülasyonun yüksek olduğu saptanmıştır (Şekil 2).

Bu çalışmada Bursa siyahı bahçesine tuzak asılmadığı için ergin sayısı bakımından çeşitleri karşılaştırmak mümkün olmamıştır. Bu konuda yapılmış bir çalışmada Irak'ta, Bursa siyahı çeşidinin (34.30 ergin/tuzak) Kuzey Batani çeşidinden (14.00 ergin/tuzak) daha fazla ergin çektiği (Abdullah ve Fandy, 2006), Slovenya'da özellikle siyah incir çeşitlerinde zararın görüldüğü bildirilmiştir (Rot ve ark., 2017).

\section{Meyvede yumurta popülasyonu}

Silba adipata ile diğer dipter türlerinin larva ve yumurtalarını ayırmak mümkün olmadığından 2011 ve 2012 yıllarında elde edilen veriler değerlendirilememiştir. Silba adipata ile Ceratitis capitata Wiedemann (Dipt.:Tephritidae) larva ve pupalarının çok benzediği, larvada sadece arka stigmaların farklı olduğu kayıtlıdır (İyriboz, 1940; Giliomee ve ark., 2007). Aynı şekilde $S$. adipata ile Lasiambia fycoperda Becker'nın (=Oscinosoma discretum Bezzi) (Dipt.:Chloropidae) yumurtaları da birbirine benzer yapıdadır. Bu nedenle ancak, çalışmanın üçüncü yılında elde edilen literatür (Silvestri, 1917) yardımıyla $S$. adipata'nın yumurta popülasyonunu izlemek mümkün olmuş, sayımlar 27 Mart-29 Aralık 2013 tarihleri arasında gerçekleştirilmiştir. İlk yumurta 1 Mayıs'ta boğa ve ilek meyvelerinde, son yumurta 9 Ekim tarihinde boğa meyvesinde saptanmış, ortalama yumurta sayısı/meyve; boğa meyvelerinde 1 Mayıs tarihinde $3 ; 28$ Ağustos $0.5 ; 4$ Eylül 0.6; ebe meyvelerinde 24 Temmuz 0.2; 7 Ağustos 0.4; 4 Eylül 19.5; 11 Eylül 5.0; 18 Eylül 26.7; 29 Eylül 40.8; 2 Ekim 12.5; ilek meyvelerinde 1 Mayıs $0.2 ; 8$ ve 15 Mayıs ile 5 ve 12 Haziran tarihlerinde 0.4 ; iyilop meyvelerinde 12 Haziran 0.1; 19 Haziran 0.3; 3 Temmuz 2.6; 10 Temmuz 0.1; 24 Temmuz 28.2; 21 Ağustos 0.7; 11 Eylül 3.4; 18 Eylül 26.4; 25 Eylül 8; 2 Ekim 12 ve 9 Ekim tarihinde 2.4 adet olarak belirlenmiştir. Çalışma sonucunda yıl boyunca en çok yumurtanın ebe meyvelerine bırakıldığı, onu sırasıyla iyilop, boğa ve ilek meyvelerinin izlediği saptanmıştır. Benzer şekilde Katsoyannos (1983), erginlerin özellikle ebe meyvelerine yumurta bıraktığını bildirmiştir. Ülkümen ve ark. (1948) bir meyvede 3-7 adetlik kümeler şeklinde 20-40, Katsoyannos (1983) 50'den fazla, Silvestri (1917) ilkbaharda 1-4, yazın 50-100 adet yumurtanın bulunduğunu, yumurta bırakılan yerin meyve sineklerinde olduğu gibi işaretlenmediğini, aynı meyveye birden fazla dişinin yumurta bırakabildiğini bildirmiştir. Dişi incir ağaçlarında nisan başında görülen yellop ve ağustos ortasında görülmeye başlayan sonlop meyvelerinin sayılarının çok az olması ve genellikle olgunlaşmadan dökülmeleri nedeniyle, yapılan düzenli sayımlarda yumurtaya rastlanmamıştır. Boğaların kış meyvesi olması, S.adibata'nın toprakta pupa döneminde kışı geçirmesi ve ilek meyvelerinin olgunlaştığı dönem olan haziran ayına kadar kışlaktan çıkan ergin sayısının az olması bu meyvelerde yumurta sayısının az olmasının nedenidir.

\section{Larva ve Pupa gelişme süreleri}

Yumurtadan çıkan larvanın toplam gelişme süresini belirlemek amacıyla yapılan çalışmalarda larvaların üzerine bırakıldığı meyvelerin kuruması larvaların ölümüne neden olduğundan az sayıda bireyden sonuç alınabilmiştir. Toplam 10 adet larvada toplam gelişme süresi $8.18 \pm 1.35$ gün olarak belirlenmiştir. Tek tek kültüre alınan larvaların pupa olmasından sonra pupa gelişme süresi $7.84 \pm 0.13(n=13)$ gün olarak belirlenmiştir. Ülkümen ve ark. (1948), haziran ayında pupaların 8-10 günde açıldığını, Katsoyannos (2009) olgunlaşmamış bir meyveden 63 adet pupa, İyriboz (1940) ise 35 larva elde ettiklerini bildirmişlerdir. Farklı olarak bu çalışma sırasında meyve içerisinde pupaya rastlamamakla birlikte, iki örnekte meyve kabuğunun kurumasıyla, kabuğu delip çıkamayan larvaların meyve içerisinde pupa oldukları ve öldükleri görülmüştür.

Ergin ömrü ve bir dişinin bıraktığı yumurta sayısını belirlemek amacıyla laboratuvar ve doğal koşullarda yapılan denemelerden sonuç alınamamıştır. Erginler 1-2 gün içerisinde ölmüştür. Benzer şekilde Katsoyannos (1983), laboratuvar ve doğal koşullarda yapılan kafes içerisindeki 


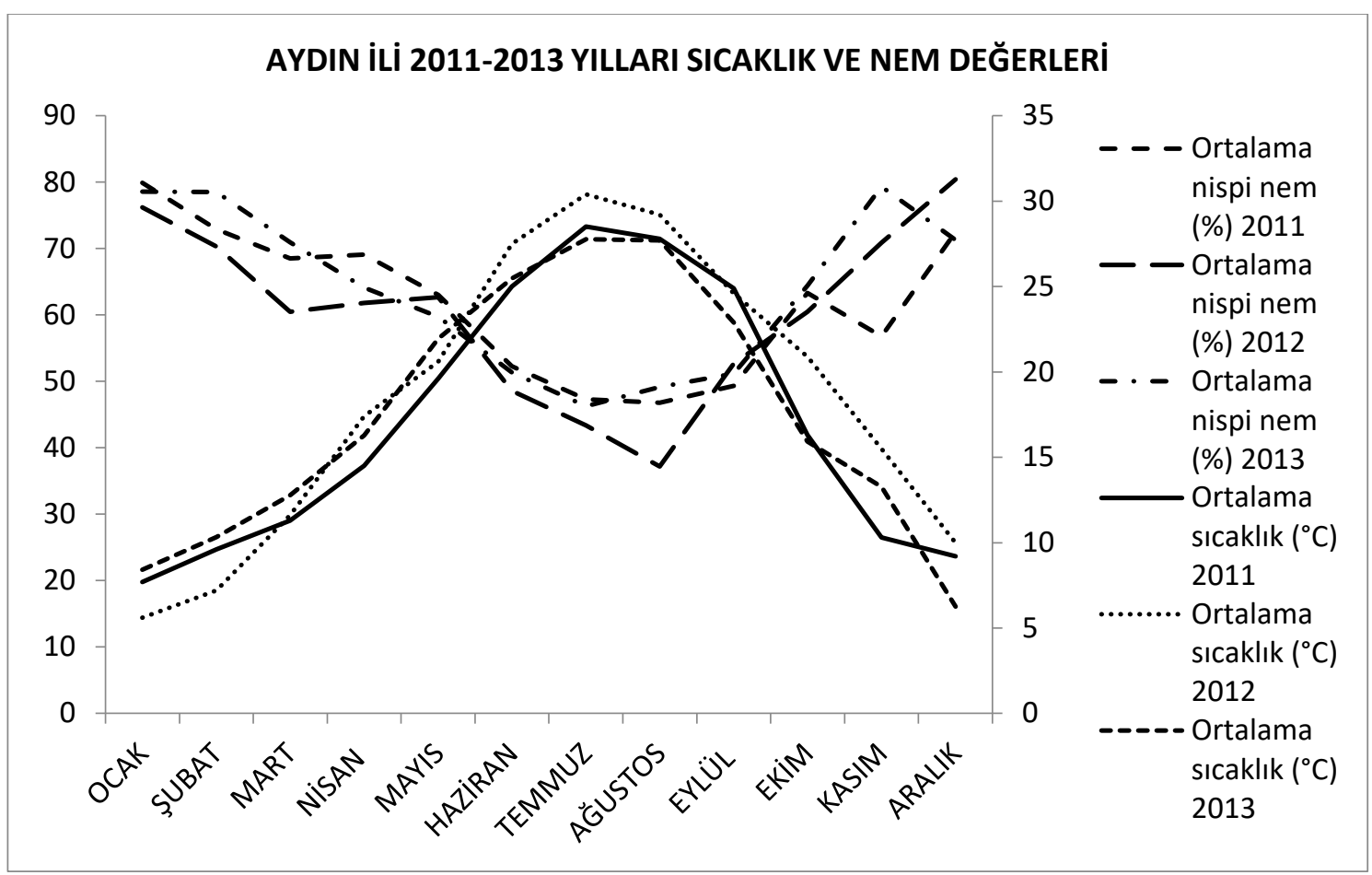

Şekil 2. Aydın iline ait 2011, 2012 ve 2013 yıllarının sıcaklık ve nispi nem değerleri

denemelerden sonuç alınamadığını, bunun S. adipata'yı da içeren çok sayıda Lonchaeidae türünde görülen sürü oluşturma davranışının deneme ortamında gerçekleşememesinden kaynaklanmış olabileceğini ifade etmiştir.

\section{Eşey oranı}

Sarılop incir bahçesinde deneme süresince tuzaklara yakalanan erginlerde seksüel indeks 0.7 olarak saptanmıştır. Benzer şekilde Katsoyannos (1983), amonyumsülfat içeren tuzaklar ile su, incir sütü karışımı içeren tuzaklarda dişi sayısının erkek sayısından fazla olduğunu, Katsoyannos ve Guerin (1984) hexanol içeren tuzaklarda dişi/erkek oranının 3:1 olduğunu, Gonçalves ve ark. (2008) Portekiz'de dişi sayısının fazla olduğunu bildirmişlerdir.

\section{Doğal Düşmanlar}

Çalışma süresince sadece 2012 yılında S.adibata larvasını taşıyan bir karıncaya rastlanmıştır. Benzer şekilde Ülkümen ve ark. (1948) Cremastogaster türünün (Hym.:Formicidae) pupa olmak için toprağa inen larvalar ile yere düşmüş incir meyvelerinin içerisindeki larvalarla beslendiğini ve yuvasına taşıdığını kaydetmiştir. Silba adipata'nın pupa parazitoiti Pachycrepoideus vindemmiae Rondani (Hym.: Pteromalidae) Fransa (Séguy, 1932) ve Yunanistan (Katsoyannos, 1983; 2009)'da saptanmış, Güney Afrika'da ise doğal düşmanına rastlanmamıştır (Giliomee ve ark., 2007).
Sonuç olarak Aydın İlinde incir üretilen tüm ilçelerin S.adipata ile bulaşık olduğu, larvaların ham incir meyvelerinde galeri açarak beslendiği ve özellikle iyilop meyvelerinin dökülmesiyle ekonomik düzeyde kayıplara neden olduğu belirlenmiştir.

Ergin ve yumurtalar dişi ve erkek incir bahçelerinin her ikisinde de yıl ve lokasyona göre değişmek üzere mayıs başından aralık ayının ortasına kadar görülmüştür. Erkek incir bahçesinde ergin popülasyonu en yüksek düzeye eylül, ekim, Sarılop bahçelerinde ise temmuz, eylül aylarında ulaşmıştır. Kış aylarında erginlerin doğada çok az sayılarda bulunduğu (aralık ve şubat) belirlenmiştir.

Dişi incir bahçeleri içerisinde ve yakınında erkek incir bahçelerinin bulunmaması, ilekleme sırasında $S$. adipata ile bulaşık meyvelerin kullanılmaması zararlının bulunma ve yayılmasını engelleyici önlemler olarak görülmektedir. Zararlının yoğun olduğu bahçelerde ihtiyaç duyulduğunda kimyasal uygulamanın; erkek incir bahçelerinde ergin yoğunluğunun fazla olduğu eylül, ekim aylarında, dişi incir bahçelerinde ise ileklemeden sonra ve meyveler olgunlaşmadan önce, temmuz ayında yapılabileceği kanısına varılmıştır. Fakat bu konuda ayrıntılı çalışmaların yapılmasının gerekli olduğu düşünülmektedir. Hexanol, amonyumsülfat ve incir sütü karışımını içeren McPhail tuzaklarıyla zararlının ergin popülasyonunun izlenebileceği ve erginlerin kitle halinde yakalanması konusunda çalışmaların sürdürülmesinin yararlı olacağı kanısına 
varılmıştır. Bursa siyahı çeşidinde de ayrıntılı çalışmaların yapılmasının yararlı olacağı düşünülmektedir.

\section{TEŞEKKÜR}

$\mathrm{Bu}$ makale Eşref TUTMUŞ tarafından hazırlanan yüksek lisans tezinin bir bölümü olup, Tarım ve Orman Bakanlığı Tarımsal Araştırmalar ve Politikalar Genel Müdürlüğü (TAGEM-BS-11/04-05/01-17) tarafından desteklenmiştir. Desteklerinden dolayı TAGEM birimine teşekkür ederiz.

\section{KAYNAKLAR}

Abdullah SI, Fandy KT (2006) Effect of Some Attractive Bait Traps and Independent Factors in Population Density of Fig Fly Fruit Silba virescens (Macq.) (Lonchaeidae: Diptera) in Nineveh Province Iraq. Arab Journal of Plant Protection, 24: 41-44.

Bora T, Karaca I (1970) Kültür Bitkilerinde Hastalığın ve Zararın Ölçülmesi. Ege Üniversitesi Ziraat Fakültesi, Yardımcı Ders Kitabı Yayın No. 167.

Condit IJ (1947) The Fig. Chronica Botanica Company, Waltham.

Ferguson L, Michailides TJ, Shorey HH (1990) The California Fig Industry. Horticultural Reviews, 12: 409-490.

Giliomee JH, Venter E, Wohlfarter M (2007) Mediterranean Black Fig Fly, Silba adipata Mcalpine (Diptera:Lonchaeidae), Recorded from South Africa. African Entomology 15(2): 383-384.

Gonçalves MA, Andrade L, Almedia L, Pica MC (2008) Study of Ceratitis capitata and Lonchaea aristella on Fig Trees. Proceedings of the Third International Symposium on Fig (May 16, 2005 Portugal) Acta Horticulturae, 79: 263-267.

İyriboz ŞN (1934) Die Feigeninsekten und Die Wesentlichsten Ursachen Der Eigenfrucht Fasele. Anz. Schädligsk, 10(10):118-119.

İyriboz Ş N (1940) İncir Hastalıkları. Ziraat Vekâleti Neşriyatı Umumi Sayı: 489, Mahsul Hastalıkları Sayı:4, Kültür Basımevi, İzmir.

Katsoyannos BI (1983) Field Observations on the Biology and Behavior of the Black Fig Fly Silba adipata Mcalpine (Diptera, Lonchaeidae), and Trapping
TUTMUŞ E, AKŞiт T Experiments. Zeitschrift Fur Angewandte Entomologie Journal of Applied Entomology, 95(5): 471-476.

Katsoyannos BI (2009) Field Observations on the Biology and Behavior of the Black Fig Fly Silba adipata Mcalpine (Diptera, Lonchaeidae), and Trapping Experiments. Journal of Applied Entomology 95(1-5): 471-476.

Katsoyannos BI, Guerin PM (1984) Hexanol: a Potent Attractant for the Black Fig Fly, Silba adipata. Entomologia Experimentalis et Applicata, 35(1): 7174.

Lazarov A, Grigorov P (1961) Karantina na Rastenijata. Zemizdat Sofia (Bulgaria).

Özar Ail, Önder P, Sarıbay A, Özkut S, Gündoğdu M, Azeri T, Arınç Y, Emir T, Genç H (1986). Ege Bölgesi'nde görülen hastalık ve zararlılarla savaşım olanaklarının saptanması ve geliştirilmesi üzerinde araştırmalar. Doğa, Türkiye Tarım ve Ormancılık Dergisi, 10(2): 263277.

Raz D (1998) The Phenology of the Fig Fly and its Control. Proceenings of the First International Symposium on Fig (June 24, 1997 İzmir, Turkey), Acta Horticulturae, 480: 207-208.

Rot M, Žežlina I, Jančar M, Seljak G (2017). Black Fig Fly (Silba adipata McAlpine, 1956 [Diptera, Lonchaeidae]) is Present also in Slovenia. Zbornik Predavanj in Referatov, 13. Slovenskega Posvetovanja o Varstvu Rastlin z Mednarodno udeležbo, Rimske Toplice, 7-8 marec,47-52.

Séguy E (1932) Diptera- Parasitologie Biologie Systematique. Recueil d'etudes sur les dipteres du globe. Tome VI, Encyclopedie Entomologique, Paris, 6: 175-176.

Silvestri F (1917) Descrizione dı una Specie dı Oscinosoma (Diptera: Chloropidae) Osservato in Fruttescenze di Caprifico. Bollettino del Laboratorio di zoologia generale e agraria della R. Scuola superiore d'agricoltura in Portici, 12: 147-153.

Ülkümen L, Özbek S, İleri M (1948). İncir ve Hastalıkları. Yüksek Ziraat Enstitüsü Basımevi, Ankara. 
